\title{
O Programa de Agentes Comunitários de Saúde no Ceará: o caso de Uruburetama
}

\author{
A case study of the Community Health Agents Program \\ in Uruburetama, Ceará (Brazil)
}

M aria $M$ arlene $M$ arques Ávila ${ }^{1}$

${ }^{1}$ Departamento de Ciências da Nutrição, Centro de Ciências daSaúde, Universidade Estadual do Ceará. Av. Paranjana 1.700, Coordenação do Curso de Nutrição, Itapery. 60740-000 Fortaleza CE. marlenemarquesavila@ uol.com.br
Abstract The program of community health agents institutionalized by the Department of $\mathrm{H}$ ealth in 1991 was the first strategy of its kind on national scale to bring attention to improving health in Brazil. In Ceará, thisprogram existssince 1986. The aim of this study is to identify and discuss the practices of health agents within the community. Interactions between a specific group of 19 infants in their first year of life from August 2004 to August 2005 and community heal th agents were followed and examined through individual interviews, focus groups, and field observations to gain a greater understanding of the common practices and the obstacles faced by these health agents. The study took placein U ruburetama, Ceará. Fifteen agents were the main source of information of this study. By looking at the analytical category of the health agent as an educator, it was empirically identified that they have an insufficient knowledge of the root causes and consequences of the social-economic determinants; and that the health practices themes and information are taken out of context of reality. This study points out the need to reinforce the training of health agents and, more importantly, strengthen their action as health educators in the community.

Key words Health agents, Primary health care practices, Popular health education
Resumo 0 Programa de Agentes Comunitários de Saúde, institucionalizado em 1991, foi a primeira estratégia para a atenção primária no Brasil, sendo a segunda o Programa Saúde da Família. No Ceará, o trabalho com agentes de saúde existe desde 1986. 0 estudo objetivou identificar as práticas das agentes em U ruburetama (CE). As técnicas utilizadas foram a observação e entrevistas. As princi pais informantes do estudo foram 15 agentes de saúde que acompanhavam 19 crianças de 0 a 12 meses de idade, no período de agosto de 2004 até agosto de 2005. A partir da categoria analítica agente educador, foram identificadas as categorias empíricas: agente de saúde com conhecimentos insuficientes; agente de saúde impotente diante dos determinantes socioeconômicos; agente porta de entrada do PSF; agente pau pra toda obra; e os temas: práticas de saúde descontextual izadas das condi ções sociais e uma relação de conflitos. Considera-se que as agentes de saúde precisam ser mais capacitadas para desenvolver suas atividades; não têm a compreensão mais ampla dos problemas vivenciados pela comunidadee lhes falta maior apoio no PSF. A ponta-sea necessi dade de reforçar a capacitação da agente de saúde, mas prioritariamente fortalecer sua ação como educadora popular em saúde.

Palavras-chaveAgentes desaúde, Práticas desaúde na atenção primária, Educação popular em saúde 


\section{Introdução}

0 presente estudo tem a finalidade de demonstrar a experiência dos agentes de saúde no Programa Saúde da Família de um município cearense. Como forma de introduzir o tema, faço uma rápida contextualização das estratégias de atenção primária em saúdeno Brasil e como ocorreu seu início e evolução no estado do Ceará.

No processo de mudança do modelo assistencial à saúde da população brasileira, duas estratégias de atenção primária à saúde têm sido utilizadas pelo M inistério da Saúde(M S): 0 Programa de Agentes Comunitários de Saúde (PACS) e o Programa Saúde da Família (PSF).

Nacionalmente, o PACS configurou-se como a primeira dessas estratégias a ser implementada, criado para ajudar na promoção e prevenção da saúde no âmbito domiciliar enível local, por meio de ações simplificadas e conforme os pressupostos da Conferência deAlma-Ata. Ao priorizar inicialmente as crianças e mulheres em idade fértil, cumpriu-se um importante papel na reorganização da atenção básica pela forma de trabalho fundamentado nas noções de área de cobertura e ações preventivas. Para isto propôs a substituição da ênfase da cura pela promoção da saúde. 0 principal ator dessa estratégia foi 0 agente de saúde.

A segunda estratégia é o PSF. Este, de acordo com o MS, deve ser entendido como: modelo substitutivo da rede básica tradicional - de cobertura universal, porém assumindo o desafio do princípio da equidade - , éreconhecido como uma prática que requer alta complexidade tecnológica nos campos do conhecimento e do desenvolvimento de habilidades e de mudanças de atitudes ${ }^{1}$.

A experiência do Programa Agentes de Saúde (PAS) no Ceará inspirou-se no Projeto Integrado de Saúde Comunitária de Planaltina, realizado em 1975 pela Universidade de Brasília, Fundação Hospitalar do Distrito Federal e Fundação de Serviço Social do Distrito Federal.

Entre 1979 e 1986, o embrião do que seria o trabal ho dos agentes de saúde no Ceará já existia no município de Jucás (CE), numa tentativa de adaptar ao sertão cearense o trabal ho desenvolvido em Planaltina (DF). Essa experiência seria posteriormenteestendida para quatorze municípios do sertão cearense, e a seguir para todo 0 estado.

Oficialmente 0 trabalho com os agentes de saúde originou-se em 1987, quando teve início uma experiência com agentes de saúde como parte do Programa de Emergência, criado em de- corrência da seca, o que ocorreu entre junho de 1987 ejunho de 1988. Para dar início ao programa em seu caráter emergencial, foram selecionadas seis mil mulheres do sertão cearense. Os critérios para essa seleção eram que as agentes de saúde fossem escolhidas entre as mulheres pobres, pois a ideia era garantir um salário mensal durante o período da seca, mas com mulheres capazes de fazer o trabalho, conhecidas e respeitadas pela comunidade, independentemente da escolaridade.

Nesse contexto, o programa originou-se como emprego de mão-de-obra não capacitada, para suprir, por um lado, a necessidade de sobrevivência de milhares de famílias e, por outro, a urgência do desencadeamento de ações capazes de ajudar a melhorar os indicadores alarmantes da saúde infantil, o que as experiências pontuais realizadas mostravam ser possível por meio de ações simplificadas.

Com a dissolução do Programa de Emergência em agosto de 1988, a repercussão do trabal ho desempenhado pelas agentes de saúde foi tanta queo governo do estado decidiu institucionalizar - agente de saúde por meio de um novo programa, o Programa Agentes de Saúde (PAS), criado pelo Decreto no 19.945 , dejaneiro de 1989, eregulamentado posteriormente pela Portaria ${ }^{\circ} 232$ / 92 epelo Decreto n ${ }^{\circ} 23.079$, defevereiro de $1994^{2,3}$.

Ao se constituir num programa do Plano de Saúde do Governo do Estado, a experiência cearense revelou-se pioneira no Brasil, como institucionalizada e universalizada, pois embora 0 trabalho com agentes de saúde já existisse em vários países, e mesmo no Brasil, faltava-Ihe a institucionalização ea universalização.

Para implantar o PAS, o município era obrigado a contratar um profissional de saúde para supervisionar o programa, não necessariamente um profissional de enfermagem. Gradualmente, porém, esse profissional foi assumindo a liderança do trabalho, o que se caracterizou como a interiorização do(a) enfermeiro(a) via PAS.

Por volta de 1989-1990, com o processo de descentralização, os municípios começaram a assumir a gestão da saúde e passaram a contratar mais médicos e mais enfermeiros e, em menor escala, outros profissionais, como dentistas efarmacêuticos. Dessa forma, no Ceará a transição PAS/PSF ocorreu de forma natural, uma decorrência da própria demanda criada pelos agentes de saúde.

Assim é que, lançado oficialmente no Brasil em maio de 1994, no Ceará, a experiência do PSF já acontecia em alguns municípios desde 1993. 
De acordo com os dados do SIAB/CE, no ano de 2002 todos os municípios já contavam com equipes de saúde da família, num total de 1.097 equipes em todo o estado; atualmente esse número passou para 1.320 equipes ${ }^{4,5}$.

São inúmeras as atribuições sob a responsabilidade dos agentes comunitários de saúde(ACS), e podemos classificá-las em três grande grupos: ações de prevenção e promoção da saúde, ações demediação entreo serviço de saúdee osusuários e ações de acompanhamento e reabilitação.

Ao definir o agente desaúde como um "agente de mudanças" ${ }^{\prime}$, a par de ser um educador, 0 MS deixa antever que as ações educativas promovidas por esse agente estão calcadas na educação popular, proposta que no Brasil teve como grandereferência o educador Paulo Freire. É, pois, nesta perspectiva que abordarei o trabalho realizado pelos agentes de saúde.

Considero que o principal atributo para 0 agente de saúde desempenhar a maior parte de suas atividades é que ele seja essencial mente um educador em saúde, uma vez que a competência com que ele realizará suas atividades depende desse atributo. Tendo isso como pressuposto, foi objetivo deste estudo caracterizar as ações realizadas pel os agentes de saúde a partir da categoria analítica: agente educador.

\section{O percurso metodológico}

Com relação ao campo da pesquisa, o estudo realizou-se em U ruburetama (Ceará), município com 19.462 habitantes, com Gestão Plena daAtenção Básica e com $100 \%$ da população coberta por cinco equipes de saúde da família (ESF), com um total de trinta agentes de saúde. A escolha do local foi por meio de dois critérios: um critério epidemiológico - em 2002, o município ficou entre os treze que tiveram segundo o SIAB-CE uma alta taxa demortalidadeinfantil ( $>40 / 1.000$ ) - e o critério da viabilidade. Uruburetama era, entre os treze, o mais próximo de Fortaleza, o que favoreceria a pesquisa de campo. Defini como grupo a partir do qual pesquisaria sobre as atividades dos agentes de saúde as crianças de 0 a 12 meses, por serem privilegiadas por uma série de atribuições próprias das ACS, e muito próximas da minha área de atuação profissional - a nutrição, ou guardando estreita relação com esta, como: acompanhamento a gestantes e nutrizes, controle das doenças diarreicas e das infecções respiratórias agudas, incentivo ao aleitamento materno, acompanhamento do desenvol- vimento e crescimento da criança, orientação quanto a alternativas alimentares.

Dessa forma, o grupo a partir do qual investiguei o trabal ho das agentes de saúde foi formado inicialmentepor 23 crianças nascidas em agosto de2004, identificadas pela D eclaração de N ascidos Vivos, ou pelas agentes de saúde, no caso de crianças que não nasceram no hospital municipal. Desse total, houve quatro perdas por motivo de mudança do município ou por o local de domicílio ser de difícil acesso, então o grupo final constituiu-se de 19 crianças que foram acompanhadas até completarem um ano de idade, em agosto de 2005.

Com relação aos informantes, foram 15 agentes de saúde, quatro enfermeiras e o coordenador do PSF no município.

Sobre a coleta e o registro das informações, foram real izadas entrevistas individuais e coletivas ea observação participante. A entrevista individual teve por fim obter os dados de identificação, bem como o consentimento de participação na pesquisa. As agentes de saúde foram acompanhadas mensalmente durante as visitas às casas das crianças. A observação foi feita de maneira a não modificar a rotina da ACS. Para isso, a pesquisadora perguntava às agentes, em cada mês, qual o dia em que estava prevista, nas suas visitas rotineiras, a visita à família das crianças incluídas na pesquisa, e nessa data acompanhava a ACS em todas as visitas realizadas. Essa estratégia teve por fim minimizar a interferência na rotina da ACS e reduzir o risco de observar uma visita feita apenas para atender à necessidade da pesquisadora, mas acabou por enriquecer muito a pesquisa de campo. A observação também foi feita nas reuniões da PSF na secretaria de saúde e nas unidades básicas de saúde. A técnica de observação que empreguei foi participante, uma vez que coletei os dados mediante minha participação na atividade rotineira das agentes e interagi com 0 grupo ${ }^{7,8}$. U tilizei como forma deregistro das observações o diário decampo. A entrevista coletiva foi uma forma de trazer para o grupo a discussão do que observei e conversei com cada uma em particular, com a finalidade de aprofundar mais meu conhecimento do grupo e suas práticas?. A forma de registro utilizada foi a gravação. Com os(as) enfermeiros(as) e coordenador do PSF, foi feita uma entrevista no final da pesquisa de campo.

Sobre a análise das informações, foram construídas as taxonomias ${ }^{10}$ a partir das entrevistas individuais e observação participante, tendo sido identificadas as categorias empíricas: "agente de saúde com conhecimentos insuficientes", "agente 
de saúde impotente diante dos determinantes socioeconômicos", "agente porta de entrada do PSF" e "agente pau pra toda obra". A pós a identificação das categorias empíricas, foram realizadas as entrevistas coletivas. 0 debate em torno das questões lançadas apontou para a identificação dos temas: "práticas desaúde descontextualizadas das condições sociais" e "uma relação de conflitos", os quais foram identificados pela sua recorrência em cada uma das categorias empíricas.

\section{Resultados}

Todas as agentes de saúde (AS) acompanhadas eram mulheres, daí semprequemereferir especificamente ao grupo estudado, o farei no feminino.

Durante todo o tempo em que acompanhei as AS e participei de suas atividades, fui sempre bem acolhida. Estive com elas nas casas das famílias, nas reuniões na secretaria de saúde, nas unidades de saúde, e em suas próprias casas, onde as encontrava para começarmos a rotina das visitas.

A primeira reunião teve a intermediação de uma agenteadministrativa da Secretaria M unicipal de Saúde incumbida pela secretária de saúde de apresentar-me ao grupo. N essa ocasião expus que $o$ interesse do estudo era conhecer melhor 0 trabalho realizado por elas, especialmente as ações com as crianças menores de um ano de idade. Para isso, expliquei queteria que acompanhá-las em algumas atividades, sobretudo nas visitas às casas das mães de crianças nascidas em agosto/ 2004, mês do início da pesquisa. A princípio, algumas delas mostraram-se desconfiadas. Entretanto, essa desconfiança inicial foi vencida, e a relação que conseguimos estabelecer foi muito boa, tanto com as AS como com os servidores da secretaria, de forma geral.

Após a reunião inicial com as AS, passei a encontrá-las mensalmente. Uma vez a cada mês ficava durante sete a oito dias em Uruburetama, normalmente na última semana do mês, quando as agentes visitavam as famílias com crianças menores de dois anos, para coletar o peso. Como as reuniões para a avaliação mensal ocorriam sempreno último diaútil do mês ou no primeiro do mês seguinte, eu podia observar essa reunião, bem como outras que ocorressem envolvendo as AS.

Na primeira vez em que saía com uma agente, fazia uma entrevista semiestruturada. Além de fornecer al gumas informações sobre a agente de saúde, esta era uma forma de iniciar um contato mais pessoal com cada uma delas. A partir de então, a observação de suas atividades era registrada no diário de campo, dando os subsídios para a descrição e análise.

Como principais aspectos observados, menciono os seguintes: a forma como as AS abordavam as mães e/ou outras pessoas nas residências, o tipo de orientação dada em face das diversas situações expostas pelas pessoas, o tratamento dispensado às crianças, os procedimentos para a coleta do peso, as orientações diante do peso identificado, a verificação do cartão da criança e os encaminhamentos feitos, se observavam aspectos da moradia e higiene, principalmente das crianças, e condutas tomadas, se eram dadas orientações sobrea alimentação da criança equais eram.

Entreas quinzeAS, duas eram solteiras e sem filhos; treze eram mães de família e, entre estas, duas já eram avós. Em relação à educação formal, uma tinha concluído o curso de pedagogia; dez concluíram o ensino médio; duas o ensino fundamental completo e duas tinham o ensino fundamental incompleto.

As condições socioeconômicas do grupo de crianças acompanhadas eram semelhantes. Em relação à situação financeira, apenas duas famílias tinham rendimentos que as caracterizava como vivendo acima da linha de pobreza (utilizando a referência do Banco Mundial, considera-se abaixo da linha de pobreza as pessoas que vivem com um dólar/dia); a maioria das mães era do lar, apenas três exerciam atividades remuneradas fora de casa; quanto à escolaridade, a maioria tinha o ensino fundamental incompleto.

O número de famílias acompanhadas por AS variou de 90 a 333, ou seja, aproximadamente 450 a 1.665 pessoas, número bem acima do preconizado pelo $\mathrm{M} \mathrm{S}^{6}$.

A partir da categoria analítica agente educador, que encontra sustentação em vários documentos oficiais que caracterizam e regulam as atividades realizadas pelos agentes de saúde, foram identificadas quatro categorias empíricas.

Em vários documentos oficiais, os ACS têm suas atividades definidas como promotoras e preventivas, além de serem orientação e elo entre comunidade e serviço de saúde ${ }^{6,11,12}$. Essas são tipicamenteações que requerem a ação de educar para se realizar. Mas como a prática da agente educadora se concretiza?

0 capítulo 1 do manual " 0 trabalho do agente comunitário de saúde", já citado, tem como epígrafe uma citação de Paulo Freire, enquanto o capítulo 2 nomeia o agente de saúdecomo "agente de mudanças". De onde deduz-se que as ações dos agentes de saúde, na condição de educado- 
res, se inspiram nateoria do conhecimento como instrumental necessário, embora não suficiente por si só, para a transformação da realidade, por meio do reconhecimento dessa teoria ${ }^{13}$.

A pesar de as experiências de educação popular em saúde terem composto o ideário do movimento da reforma sanitária, a política de saúde manteve como pressuposto de atenção à saúdeo modelo biomédico que determina a separação cultural entre serviços de saú de e população ${ }^{14}$.

Para agir como educador(a) popular em saúde énecessário conhecer, compreender o contexto socioeconômico e cultural, instrumentalizarse, enfim, para exercer esse papel. Com vistas a essa aquisição, as agentes de saúde precisariam passar por um processo de formação que as habilitasse para tal e lhes possibilitasse compreender o sistema no qual estão inseridas, bem como os fatores sociais, econômicos e políticos implicados nas condições de vida, suas e das famílias por elas acompanhadas como determinantes do estado desaúde/doença. Esse instrumental éfundamental para qualquer trabalhador de saúde da atenção primária, nível em que a saúde deve ser trabalhada a partir de um conceito amplo e do ponto de vista de seus diversos determinantes ${ }^{15}$, elocus ondeo princípio da participação deve ser cultivado.

Contudo, esse ponto crítico - o da capacitação ampla - ou de sua falta fica evidenciado em diversas falas das agentes de saúde, e se constitui na principal característica das categorias empíricas identificadas na prática das agentes como educadoras, as quais passo a descrever.

Agente de saúde

com conhecimentos insuficientes

O despreparo para lidar com os problemas da população evidenciou-se em muitos depoimentos das agentes de saúde. 0 desconhecimento de como lidar com al guns dos condicionantes de saúde na comunidade limita suas ações.

Para trabalhar alguns desses condicionantes são necessárias ações integradas com outros setores, por exemplo a secretaria de educação, o serviço de limpeza urbana, a vigilância sanitária, o que não é uma prática da equipe de saúde da família. Dessa forma, as agentes compreendem que vários condicionantes de saúde estão além de suas ações rotineiras, mas não vislumbram formas de estender suas ações.

Ao utilizar noções inadequadas sobre a ocorrência das doenças, como "a diarreia é normal na dentição" e "a infecção respiratória acontece muito devido a mudança de clima", a agente de saúde pode reforçar nas mães a percepção de que é "normal" a criança adoecer, além do que reduz a importância de cuidados como a higiene pessoal e do lar, bem como dos cuidados com a higienização epreparo dos alimentos, o quepode ter repercussões importantes para a saúde da criança fragilizada.

Em relação a alimentação e nutrição, são muitos os pontos frágeis, desde a prática do aleitamento materno, com a introdução inadequada da alimentação complementar, quer seja em relação ao tempo - algumas mães introduzem outro alimento já no primeiro mês -, quer seja em relação ao tipo e preparo do alimento, como 0 uso inadequado de espessantes do leite (amido) e a diluição incorreta do leite artificial, até conhecimentos sobre quais al imentos podem ser consumidos no primeiro ano de vida e como devem ser preparados visando não só ao seu melhor aproveitamento mas também a sua utilização pelo organismo.

Outra ação em que faltam mais conhecimentos específicos é o acompanhamento do crescimento edesenvolvimento infantil, uma das principais ações básicas de saúde realizadas pelas agentes. Conforme o previsto, o monitoramento do crescimento e desenvolvimento é realizado mensalmente. Tal como preconizado pelo M S, o agente de saúde acompanha o desenvolvimento físico e psicológico das crianças de zero a cinco anos de idade por meio do Cartão da Criança ${ }^{16}$. 0 crescimento pela evolução do peso e o desenvolvimento, via aquisições cognitivas e motoras esperadas para cada idade, estão descritos de forma simples no Cartão da Criança e devem ser observados e anotados nesse documento. Além disso, devem ser ensinadas às mães formas de estimular o desenvolvimento de tais aquisições.

Na prática, porém, o que se percebe é que as ações relacionadas ao desenvolvimento não são efetivadas. $N$ ão tive oportunidade de sequer uma vez observar a agente de saúde fazer al guma anotação na parte do cartão destinada a isso, ou conversar com as mães sobre o desenvolvimento da criança, apesar deal gumas apresentarem evidente atraso cognitivo e motor. Em relação ao crescimento, as agentes de saúde procuram fazer 0 acompanhamento mensal, mas foram observadas algumas limitações nessa ação, relacionadas com aspectos técnicos: o desconhecimento da necessi dade de calibração da balança e da variação de peso consequente do uso do instrumento de forma inadequada, o que se relaciona com a aferição incorreta do peso e consequentemente 
erro no diagnóstico do estado nutricional; a inabilidade para construir a curva do crescimento, não refletindo esta, em algumas das crianças acompanhadas, a evolução real do crescimento, e a falta de esclarecimento à mãe do significado da curva como reflexo da saúde infantil.

Um aspecto que vale salientar é a tendência observada da análise do peso, que só é interpretado como um problema quando está abaixo do considerado normal, ou seja, se a criança estiver perdendo peso ou desnutrida; quando está acima do peso, mesmo que muito acima, isso não é analisado como problema, porque ainda está incutida a noção de que a "criança gordinha" é sinônimo de "criança saudável".

De maneira geral, as limitações identificadas nessa categoria foram de todas as agentes. Aquelas com maior escolaridade apresentavam mai or desembaraço, por exemplo, na construção da curva do crescimento, porém em relação ao aleitamento materno enfrentavam as mesmas dificuldades. Entre as mães que introduziram o leite artificial já no primeiro mês de vida da criança, havia aquelas acompanhadas por agentes que tinham o ensino fundamental incompleto, mas também al gumas acompanhadas por agentes que haviam concluído o ensino médio e atéo terceiro grau - bem como era também de todo o grupo a incapacidade de fazer a orientação adequada da alimentação complementar, ensinando, por exemplo, a introdução de alimentos que se encontravam disponíveis para a família na al imentação do lactente.

Além dos aspectos identificados como de difícil manejo pelas agentes de saúde por limitações em alguns conhecimentos específicos, outros existem, cuja limitação é determinada pelo contexto socioeconômico em quevivem as famílias, o que nos leva à identificação da segunda categoria empírica.

Agente de saúde impotente

diante dos determinantes socioeconômicos

As condições de vida da população acompanhada pelas agentes de saúde neste estudo caracterizam-se pela pobreza, falta de alimentos, condiç̧ões de moradia insal ubres, água contaminada, lixo, inexistência de recursos, fatores a serem considerados no planejamento das ações de saúde no nível local e questões com as quais as agentes sentem-se impotentes paralidar. Deacordo com os depoimentos das agentes de saúde, essas questões vão além do alcance das ações de saúde tais como são realizadas. Portanto, a pro- moção da saúde ainda é algo a ser conquistado, e não uma característica da atenção primária no município. Isso fica patente nas dificuldades das agentes de saúde no enfrentamento de problemas como a falta de saneamento básico, as condições dehigiene: pessoal, do domicílio edo meio ambiente; além das doenças em que as causas mais relevantes são relacionadas aos determinantes socioeconômicos, como na desnutrição.

Ao identificar uma criança desnutrida, o procedimento é encaminhá-la para o médico. No entanto, isso não impede que a criança continue a perder peso. Outra medida que a agente de saúde pode lançar mão é ensinar a dieta aconselhada no manual, porém muitas vezes a mãe não tem como fazer porque não dispõe do alimento, ea agente de saúde fica sem alternativas. $N$ o caso da desnutrição, existe a concepção da influência de outros determinantes, além da falta de alimentos, porém elas sentem-se impotentes e reconhecem que nada éfeito.

Há outras doenças citadas pelas agentes de saúde, como as diarreias e a desidratação, para as quais se sentem impotentes porque fazem a relação de sua ocorrência com aspectos que ou estão fora de seu alcance ou são difíceis de mudar, como por exemplo a falta de saneamento básico, o consumo deágua contaminada, a questão da higiene e fatores culturais. A pesar de trabalhar alguns desses aspectos, existe a percepção de que "nada adianta porque é da própria criação; se nasceu e cresceu na casa limpa, vai reproduzir, se não...".

O sentimento deimpotência evidencia-seem depoimentos que frisam a limitação de sua participação na resolução dos problemas na comunidade: "Ser agente de saúde é participar da comunidade, discutir seus problemas e como ajudar... mas como ajudar se não tem recurso?"

Essa impotência vivenciada pelas agentes de saúde édo próprio sistema, diante de problemas que demandam o envolvimento de outros setores, a prática da intersetorialidade, a integração das ações, no sentido da promoção e prevenção.

Ao se referir às dificuldades de se avançar na intersetorialidade, Fernandes ${ }^{17}$ reflete que a forma como o setor saúde está organizado é um ponto positivo para seavançar nesse aspecto, pois os problemas deum território desaúde devem constituir o lócus no qual os diferentes setores de políticas públicas - e Ongs daquele território - repensem suas práticas e organizem suas ações.

No grupo de crianças do estudo não houve ocorrência de desnutrição. No entanto, de acordo com as agentes de saúde, esse é um dos pro- 
blemas de difícil solução para o conjunto das famílias acompanhadas. Diante de tal situação, as AS se defrontam com o complexo desafio de ajudar às mães de crianças desnutridas. $M$ as 0 que fazer quando a doença é consequência das condições de vida das pessoas? A quem recorrer? Onde buscar as alternativas de cura?

Sobre essa questão específica, há ainda outro agravante na opinião da enfermeira de uma das equipes: "Existe falha na detecção do problema porque as agentes de saúde não sabem avaliar".

Como contaponto a essa percepção da profissional de enfermagem, nessa categoria sobressai a falta de apoio por parte da PSF, ressentida pelas agentes. Ademais, são mencionadas questões nas quais elas são chamadas a ajudar a resolver, mas o caminho da solução não Ihes é dado: "A gente tem muita cobrança dos nossos chefes, do nosso superior. Eles repassam muita coisa que não dá pra resolver..."

Um exemplo disso foi dado por uma agente de saúde ao relatar que uma de suas responsabilidades era, segundo o gerente da microrregional de saúde, reduzir o numero de gestantes menores de 20 anos em sua área: 0 gerenteda $\mathrm{M}$ icro fez uma reunião e colocou como meta reduzir em 2005 o número de gestantes menores de 20 anos porque em 2004 foi muito alto o número de gravidez nesta faixa etária. "Tem quebaixar", mas não diz como...

N esse contexto, o que podea agente de saúde fazer além de se angustiar com a situação, cuja solução foge à sua competência? Entretanto, ela está ali a vivenciar o problema juntamente com a família, todos os dias.

Esse sentimento deimpotência das agentes de saúde tem suas causas num contexto bem mais abrangente, na prática de um novo modelo de atenção no qual todos os profissionais são aprendizes. Ao ser eferir à reforma das práticas em saúde, Campos $^{18}$ afirma: Ainda não conseguimos, historicamente, realizar a negação/superação das práticastradicionais; ou seja, maisas criticamos eapontamos seus limites do que fomos capazes de construir propostas alternativas de atenção. Passada quase uma década, essa constatação continua válida, pois apesar de o tema educação dos profissionais de saúde estar em pauta, fatores importantes como problematizar a educação como agenda da gestão, a avaliação dos cursos que proliferam na pós-graduação stricto sensu, a avaliação e o acompanhamento dos cursos de graduação na área da saúdenão têm sido privilegiados ${ }^{19}$.

Nessa categoria, todas as agentes de saúde apresentaram as mesmas dificuldades. A influência da escolaridade podia ser percebida numa maior compreensão dos condicionantes sociais da saúde da população, mas isso não significava uma forma diferenciada de enfrentamento das questões identificadas.

Os aspectos implícitos nas categorias "agente com conhecimentos insuficientes" e "agente impotente diante dos determinantes socioeconômicos" caracterizam o tema "Práticas de saúde descontextualizadas das condições sociais", sobre 0 qual passo a tecer algumas considerações.

O MS trabal ha na atenção primária com diretrizes formuladas do ponto de vista da necessidade de mudança de comportamento, ou seja, do indivíduo culpado pelas suas mazelas. Assim, os agentes de saúde devem orientar as pessoas quanto aos cuidados de saúde, sobre como manter a sua saúde, de suas famílias e de sua comunidade, compreendendo a relação entre as doenças e estilos e hábitos de vida ${ }^{16}$.

No caso, o estilo de vida é a pobreza e os hábitos por ela impostos. Na perspectiva do MS, a vulnerabilidade social em que vivem essas famílias é deixada de lado, frustrando a característica da APS de trabalhar a saúde do ponto de vista dos seus diversos determinantes (meio social, físico, características culturais e comportamentais). Esse é o desafio posto: as dificuldades enfrentadas pela agente de saúde como educadora na verdade afrontam todos os profissionais da atenção primária. Sobre o assunto, Santo ${ }^{20}$ afirma: há obstáculos que mesmo uma equipe intei ra de profissionais de saúde não pode contornar: a miséria. Não é tradição no Brasil, pelo menos não é a regra, a saúde ser trabalhada em sua interface com demais setores. Isso é particularmente verdadeiro no campo deste estudo, em que, por exemplo, as questões relativas ao saneamento ambiental e fornecimento de alimentos, claramente implicadas no perfil de saúde do município, não são trabalhadas em conjunto. 0 sentimento de impotência das agentes de saúde têm aí sua origem, assim como também o que elas percebem como falta de resolutividade do serviço, por exemplo o acompanhamento das crianças desnutridas: $\mathrm{Na}$ minha área tem dois, duas crianças desnutridas. 0 que a gente pode fazer é falar com os médicos e as enfermeiras, mas nunca ninguém foi na casa delas. Todo mundo vê aqui o cartão, mas não resolve nada...

As condições de saúde da população têm como maior peso os fenômenos sociais. A "causalidadeem série" referida por Herzlich eAdam ${ }^{21}$ ainda leva ao óbito infantil por diarreia, deixando a agente de saúde perplexa, à cata de culpados, porque ela, ciente de ter tomado as medidas 
cabíveis, não pode ter a culpa: “... ano passado morreu uma criança de desidratação, fiquei arrasada, mas não foi culpa minha, acho que foi descaso do hospital".

Conforme observado, a lógica assistencial no estabel ecimento da oferta dos serviços e necessidades da população não considera os fenôme nos sociais e as condições por eles impostas. Stotz $z^{22}$ pondera que as relações sociais e os aspectos culturais não são considerados pelo sistema social na percepção das necessidades de saúde da população.

Quanto às diretrizes do M S, são compatíveis com uma realidade: as políticas de saúde não ambicionam uma profunda transformação da sociedade. Embora não seja objetivo deste estudo discutir essa posição, cabe-me reforçar que para seavançar maisnas conquistas no campo da saúde é necessário se avançar nas ações intersetoriais.

No relacionado às limitações da agente de saúde como educadora, à sua capacitação para tal, é outro desafio, porque apesar do afirmado sobre a necessidade de mudanças sociais, isso não exclui a importância do processo educativo, a urgência de aperfeiçoar os agentes para desenvolvêlo. Segundo Freire $^{13}$, enquanto prática desveladora, gnosiológica, a educação sozinha, porém, não faz a transformação do mundo, mas esta a implica.

O utra consideração cabível diz respeito ao contexto em quea experiência de agentes de saúde surgiu no Ceará. Um programa com mão-de obra de baixo custo, com trabalhadores sem ne nhuma capacitação. Naquele contexto, as atribuições pessoais que as habilitavam para o tipo de ação a ser executada eram conhecer a comunidadee ter disponibilidade para o trabal ho diário. Algumas das agentes admitidas àquel a época ainda continuam na ativa, e são as agentes de saúde com menor escolaridadeemais dificuldades para acompanhar qualquer capacitação técnica.

A diversidade das ações realizadas pelas agentes desaúde foi o atributo para a identificação da terceira categoria empírica.

\section{Agente pau pra toda obra}

A despeito de em documentos oficiais as atribuições dos agentes de saúde nem sempre apresentarem uniformidade $e^{1,6,23-25}$, na análise dessa categoria parti das atribuições de promoção/pre venção; tratamento/reabilitação e mediação social, especificadas pelo $\mathrm{M} \mathrm{S}^{16}$.

A maior parte das atribuições definidas pelo M S caracteriza-se como ações de promoção e prevenção, al gumas das quais são de caráter co- letivo, e outras, individuais. Realizá-las exige das agentes de saúde a capacidade de desenvolver monitoramento dos indicadores de risco individual e coletivo e participar da proposição e execução demedidas deintervenção juntamentecom a comunidade.

Foram identificadas como ações de promoção e prevenção rotineiramente realizadas pelas agentes: executar, dentro do seu nível de competência, ações e atividades básicas de saúde; acompanhamento a gestantes e nutrizes; incentivo ao aleitamento materno e o acompanhamento do desenvolvimento e crescimento da criança ${ }^{16}$. Essas são atribuições percebidas pelas agentes como de menor nível de dificuldade, sendo esta, às vezes, relacionada apenas à disponibilidade detempo, em face do acúmulo de tarefas.

No entanto, constatei a existência das dificuldades relacionadas a aspectos bem mais específicos, como a falta de capacitação das agentes para algumas ações de caráter individual, identificada nas práticas de acompanhamento a gestantes e nutrizes e no monitoramento do crescimento e desenvolvimento infantil, que foram as ações mais frequentemente observadas durante as visitas com as agentes de saúde.

0 acompanhamento às gestantes ainda évisto como um desafio pelas agentes de saúde, sendo a principal dificuldade relatada o início tardio do acompanhamento pré natal. Estranhamente, a orientação do planejamento familiar é, segundo as agentes, um fator que concorre para isso, uma vez que as mulheres que participam dessa atividade e engravidam escondem o fato, vindo a agente a descobrir apenas "quando não dá mais para esconder a barriga ou quando 0 povo diagnostica".

0 monitoramento do crescimento e desenvolvimento é realizado mensalmente, mas com muitas limitações - al gumas relacionadas à falta de conhecimentos, como já vimos, e outras à falta de instrumental mínimo necessário à sua execução, como por exemplo a falta de equipamento para pesar e medir crianças maiores de 2 anos ea falta de local adequado em muitas residências para afixar a balança.

Quanto à avaliação que as agentes de saúde fazem do peso, a tendência é só analisar como um problema se estiver abaixo do esperado, ou seja, se a criança estiver desnutrida; quando está acima do peso, isso não é analisado como desvio, descaracterizando a ação como preventiva.

No referente ao al eitamento materno, o principal problema identificado relaciona-se com a falta deinteração mães/agentes de saúde. Deacor- 
do com as agentes, as mães são orientadas no período da gestação para a prática do aleitamento materno exclusivo pelo menos até a criança completar seis meses deidade. No entanto, entre as 19 crianças, todas iniciaram a alimentação complementar antes do quarto mês, e o que é mais grave: algumas já no primeiro mês de vida e sem nenhuma orientação, porque a maioria das mães esconde das agentes de saúde esse fato.

Com as características de tratamento/reabilitação, identificam-seas ações de encaminhar as pessoas doentes à unidade de saúde e o posterior acompanhamento por meio das visitas domiciliares. Essas atribuições requerem a capacidade de identificar o agravo e as medidas ne cessárias para o encaminhamento e acompanhamento dos casos.

0 que as agentes identificam como a principal dificuldade para essa ação é relacionada com a indisponibilidade dos profissionais médico(a) e enfermeiro(a): "Quando tem uma necessidade urgente da pessoa ver o médico eelenão vai, eu tenho que dar um jeito de levar a pessoa para o hospital".

Segundo Starfield ${ }^{15}$, a promoção da saúde requer a interação entre o serviço médico e os serviços sociais e ambientais. N essa perspectiva, um dos maiores entraves que as agentes enfrentam érelacionado com a necessidade, em muitos casos, das ações intersetoriais, prática ainda não característica da Estratégia Saúde da Família, sendo essa possivelmentea principal dificuldade para a realização das ações caracterizadas pelo MS como de mediação.

Com essa característica de mediação, o MS el enca uma série de ações de caráter coletivo, que demandam a capacidade das agentes de saúde de estimular, organizar e mobilizar a comunidade, atuando como agentes deincentivo da participação comunitária ${ }^{6}$. No contexto estudado, não observei a realização de nenhuma ação que pudesse ser assim caracterizada.

Entre as competências indispen sáveis a atividades de mediação, sobressaem as capacidades de desencadear ações deinteresse do bem comum com responsabilidade; de mobilizar e integrar a comunidade na ação e articular-se com os demais setores na discussão e realização das ações deinteresse coletivo.

Para desenvolver tais ações, existem nume rosas dificuldades. As principais são relacionadas com a falta de conhecimentos exigidos para ser esse articulador social, e com aptidões pessoais, como por exemplo o espírito de liderança, que a princípio seria um dos requisitos para ser agente de saúde 6 .
No entanto, ainda é na equipe de saúde da família, com o agente comunitário, que se encontra o profissional mais próximo da comunidade. Essa proximidade com as famílias e a vivência dos seus problemas são os principais componentes da taxonomia que forma a quarta categoria empírica.

\section{Agente porta de entrada do PSF}

A percepção das agentes de saúde quanto à sua importância nas duas extremidades do elo é fortemente mostrada nos vários discursos em que se denominam como a "raiz do PSF, porque sem a raiz a planta não pode crescer", e também como a porta do PSF: "porque nós somos a porta; sem nós vai demorar muito para que o médico saiba até em qual porta que ele vai bater".

Também por parte dos profissionais de nível superior da ESF, há essa percepção das agentes de saúde como porta de entrada; segundo uma enfermeira, "o papel do agente de saúde é detectar o problema e levar para o profissional de nível superior".

Segundo o M S, "o agente comunitário de saúde é um elo entre a comunidade e os serviços de saúde", é a "ponte entre as famílias, a comunidade e a unidade de saúde"

Na prátic, a verifica-sequea agenteéa profissional da equipe de saúde da família que vai rotineiramente às casas das famílias acompanhadas; é el a quem faz a comunicação entre as famílias e os demais profissionais da equipe e estabelece a relação famílias/unidadede saúde- fato queconfirmou-se plenamente neste estudo. As agentes de saúde têm a percepção de que são "o alicerce entre a comunidade e os grandes", fala que, além de ilustrar esse fato, evidencia o distanciamento entre os profissionais de saúde e esse agente-elo que liga o pequeno (a comunidade) ao grande (os profissionais de nível superior da equipe de saúde da família).

As agentes de saúde são plenamente conscientes desse seu papel de elo na ESF e sabem que os demais profissionais reconhecem isso. Porém, o termo "grande", utilizado pela agente, além de evidenciar a percepção do distanciamento serviço/clientela, aponta para uma separação agente/ profissional de nível superior enos leva à seguinte reflexão: se são assim tão importantes na equipe, por que os demais são "os grandes"? Que tipo de relação se estabelece nessa equipe para que as agentes tenham essa percepção? A elucidação dessequestionamento aponta paraum dos temas identificados. 
Uma relação de conflitos

0 excesso de atribuições das AS, a falta de capacitação para o exercício de al gumas delas ea exiguidade de tempo para o exercício de outras, mais a forma como são pressionadas em sua rotina de trabalho, tanto pelos demais componentes da ESF como pelas famílias acompanhadas, tornam conflituosa a relação ESF/agentes de saúde/famílias.

As agentes explicitam isso de várias formas, e seus depoimentos expõem o difícil equilíbrio da prática das agentes. Ora elas são cobradas pelas famílias, ora pelos demais profissionais da ESF. Às vezes as famílias não reconhecem o trabal ho realizado, nem aceitam como possíveis explicações o acúmulo de trabalho das agentes e sua impotência para lidar com determinados problemas. Porém, em relação às famílias, há a percepção das agentes de que se algumas "não dão importância ao trabalho da agente", outras "reconhecem o trabalho realizado e têm respeito e confiança".

Quanto aos conflitos na ESF, de modo geral as agentes referem que sentem falta de apoio na ESF, exemplificando essefato com a falta deacompanhamento nas ações que realizam rotineiramentee a descontinuidade das visitas domiciliares que devem ser feitas por médicos(as) e enfermeiros(as). Isso, em sua concepção, tira parte da credibilidade no trabalho dos agentes comunitários de saúde. Além disso, referem a forma como são cobradas na ESF e a falta de reconhecimento pelo trabalho realizado, aí incluída a questão da remuneração, aspecto referido por várias agentes.

Ao relacionarmos os depoimentos das agentes com o que explicitam os profissionais de nível superior da ESF, evidencia-se o confronto. 0 coordenador do PSF no município tem uma posição radical no exercício desua função, e explicita que existem dois grupos de agentes de saúde na Associação dos Agentes de Saúde: "os que têm autonomia - eles acham que têm, equestionam, são os menos responsáveis - e os que obedecem sem questionar".

São ainda causas dos principais conflitos na concepção do coordenador as faltas sem justificativa, o queé punido com o desconto do dia detrabaIho, e a falta de cumprimento das tarefas, dando como exemplo o fato de que "morre uma criançae o agente de saúde não toma conhecimento".

Do ponto de vista dos demais profissionais da ESF, são também fatores de conflito a deficiência identificada no trabalho das agentes, o queé relacionado com o "nível de escolaridade e acomodação das agentes".

Um aspecto observado e que atua negativamente para a coesão na ESF éa regularidade com a qual os profissionais de nível superior entram e saem no PSF, o que é traduzido assim por uma agente: "Os agentes de saúde estão sempre em fase de adaptação com os novos profissionais porque cada um que entra se conduz de um jeito diferente".

Dessaforma, o tema conflito na equipeseidentificou em todos os níveis, estando aí implicadas desde as relações de poder naESF atéa necessidade de reconhecimento referida pelas agentes de saúde: de serem reconhecidas pela equipe, de serem reconhecidas pela comunidade, o que é assim explicitado por uma agente: "Tem gente que me vê como nada, tem gente que me vê como tudo, tem gente que tanto faz eu como nada..."

\section{Consideraçõesfinais}

Ao se inserir no PSF, as práticas dos agentes comunitários de saúde (ACS) sofrem a influência dessa inserção, como não poderia deixar de ocorrer. A meu ver, nos estados onde é recente a experiência dosACS isso não tevegrande significação, o que não se aplica em casos como o do Ceará, onde ao ser implantado o PSF entre os agentes de saúde incorporados à equipe, havia aqueles que já atuavam há quase uma década, com relativa autonomia em suas ações. Porém, com a incorporação ao PSF, o agente passa a perceber-se apenas como o elemento que facilita o contato entre a comunidadee o serviço de saúde, como ilustra a categoria "agente porta de entrada do PSF".

N essa nova situação, exige-se desse agenteum novo perfil. M as que perfil seria esse? A função que realmente poderia desenvolver, aquela para a qual seria o profissional mais habilitado porque é a priori quem melhor conhece a comunidade, etambém pela al ta rotatividade característica dos demais componentes da ESF - obstáculo para a formação do vínculo indispensável na relação educador/educando -, seria a de educador popular em saúde, mas Ihe falta capacitação específica, como demonstraram as categorias "agente com conhecimentos insuficientes" e "agente impotente diante dos determinantes socioeconômicos".

Conforme ilustrado na categoria "agente pau pra toda obra", são muitas as ações atribuídas aos ACS na atenção primária, e os conhecimentos que eles detêm são insuficientes para 0 en- 
frentamento dos problemas com os quais se deparam em sua rotina, quer seja o conhecimento específico em saúde, quer seja o conhecimento de estratégias educativas.

0 agente educador na suposição da educação popular em saúde (EPS) é um agente capaz de contribuir com mudanças. Para tanto, é preciso que o ACS se aproprie dos conhecimentos necessários e disponha das condições favoráveis para realizar o trabal ho educativo. A capacidade de mobilizar e engajar a comunidade num processo de (auto)conhecimento éum pré-requisito de qualquer ação destinada a promover mudanças concretas e que deve ser característico não só do ACS, mas de todos os profissionais que atuam no primeiro nível de atenção.

Entretanto, práticas educativas que se caracterizem como EPS se constituem num desafio, não só para agentes comunitários de saúde, mas para os demais profissionais da ESF. As dificuldades enfrentadas pela ESF são relacionadas com a formação acadêmica. 0 despreparo dos profissionais da ESF constitui-se num dos obstáculos para trabalhar sob a ótica da APS. As atividades educativas são de responsabilidade de todos os componentes da equipe, e sua prática pelos profissionais de nível superior, regra geral, é calcada na "verdade" do saber técnico-científico, que precisa ser ensinado/imposto.

Decorrente desse modelo, a prática educativa do ACS se dá de formas verticalizada e normatizadora, características em regra das práticas educativas em saúde e em confronto com a proposta metodológica de Paulo Freire, para quem educar é um ato solidário: "não há educadores nem educandos puros"; no trabalho de educação, os dois lados ensinam e aprendem ${ }^{26}$.

0 exercício desse modelo impositivo e normatizador é também observado nas relações que se estabelecem entre os componentes da ESF; é 0 que expressa o tema "uma relação de conflitos", quedenota afragilidadedo ACS, hierarquicamente submetido aos profissionais de nível superior, submissão não explicitada em nenhum documento oficial, porém inscrita na prática da equipe, marcada pela autoridade que presumivelmente os "doutores" adquirem juntamente com o conhecimento acadêmico e que muitos - a prática assim o demonstra - fazem questão de exercitar.

Quanto ao tema "Ações de saúde descontextualizadas das condições sociais", considera-se a necessidade da capacitação dos ACS visando privilegiar sua ação como educador-facilitador.
0 fato de ser 0 agente pertencente à comunidade onde vai desempenhar suas atividades éum fator importante na sua formação como facilitador do processo educativo que deveria pautar sua prática. Ele conhecebem o meio ondedesenvolve suas ações, ena mai oria das vezes vive nesse meio. M as isso não significa ter uma compreensão maior sobre a realidade que vivencia, pois faltam-Ihe subsídios que o ajudem no processo de autoconhecimento. Sua capacitação como agente educador/facilitador deveria contribuir para uma compreensão mais profunda da realidade, de sua razão de ser como é, e de como contribuir para melhorar o que for possível, a partir da posição que ocupa na ESF. Faz falta a esse agente 0 processo educativo capaz de favorecer o desenvolvimento da criticidade necessária para estabelecer as causalidades dos fenômenos por ele vivenciados.

Deposse desses instrumentos, ele poderia ser, primeiro, um agente de mudanças onde elas forem necessárias e possíveis, e, segundo, um facilitador na promoção da participação comunitá$\mathrm{ria}^{27}$, de forma mais efetiva. Segundo Freire ${ }^{28}$, quanto mais crítica for a compreensão dos fatos, mais críticas também serão as ações no sentido de apropriação pelo homem de sua inserção no contexto, sua integração.

Em relação ao agente de saúde, há o consenso de que sua formação precisa ser rediscutida em novas bases.

Deacordo com a diretriz do M inistério da Saúde, está atualmente em curso no Ceará a capacitação destinada a qualificar o agente de saúde como técnico denível médio por meio de um curso modulado de 1.200 horas. Só poderão concluir a qualificação eassim obter o diploma detécnico denível médio os agentes quetiverem concluído o segundo grau $^{29}$. A mencionada qualificação prevêtrês etapas. A penas parte do conteúdo da segunda etapa diz respeito à educação em saúde, erequer dosagentesnumerosashabilidadesrelacionadascom o perfil deeducador. Contudo, o documento não explicita se a qualificação prevê a formação desse agente educador, parecen do antes sugerir que o agentejáé habilitado como "educador em saúde".

Insisto que é prioritário qualificar o agente de saúde como educador popular em saúde. Primeiro, torná-lo educador. Depois capacitá-lo nos temas específicos. Essa deveria ser uma diretriz para a qualificação desse trabalhador de saúde e uma perspectiva política de estratégia de atenção primária realmente inovadora. 


\section{Agradecimentos}

À Secretaria Municipal de Saúde de Uruburetama, às agentes comunitárias de saúde e às famílias que possibilitaram este estudo.

\section{Referências}

1. Brasil. M inistério da Saúde. Saúde da Família: uma estratégia para reorientação do modelo assistencial. Brasília: M inistério da Saúde; 1997.

2. M cAuliffe J. Análise crítica do Programa de Agentes de Saúde do Ceará [relatório final]. Fortaleza: SESA; 1994.

3. Brasil. Portaria $n^{\circ} 232 / 92$, de 15 de maio de 1992. Estabelece normas técnicas e operacionais de planejamento, execução, acompanhamento e avaliação do Programa de Agentes de Saúde, criado pelo Decreto Estadual $n^{\circ}$ 19.945, de 02 de janeiro de 1989, e dá outras providências. Diário Oficial [do] Estado do Ceará 1992; 19 mai.

4. Secretaria de Saúde do Estado do Ceará (SESA). Relatório de quantidade de profissionais no PACS e PSF, referente a 2003. Fortaleza: SESA; 2003.

5. Ceará. Secretaria de Saúde do Estado do Ceará (SESA). Indicadores e dados básicos para a saúde no Ceará - 2003. v. 3. Fortaleza: SESA; 2005.

6. Brasil. M inistério da Saúde. Secretaria de Políticas de Saúde. Departamento de Atenção Básica. 0 trabalho do agente comunitário de saúde. Brasília: Ministério da Saúde; 2000.

7. Becker HS. Métodos de pesquisas em ciências sociais. São Paulo: Hucitec; 1997.

8. Soriano RR. Manual de pesquisa social. Petrópolis: Vozes; 2004.

9. Gaskell G. Entrevistas individuais e grupais. In Bauer MW, Gaskell G. Pesquisa qualitativa com texto, imagem, som: um manual prático. Petrópolis: Vozes; 2002. p. 64-89.

10. Spradley JP. Participant observation. Orlando: Holt; 1980.

11. Brasil. Lei no 10.507. Cria a profissão de Agente Comunitário de Saúde e dá outras providências. Diário Oficial da União 2002; 10 jul.

12. Brasil. Decreto Federal no 3.189/99. Fixa diretrizes para o exercício da atividade de Agente Comunitário de Saúde (ACS) e dá outras providências. Diário O ficial da União 1999; 10 out.

13. Freire P. Pedagogia da esperança: um reencontro com a pedagogia do oprimido. $2^{\mathrm{a}}$ ed. Rio de Janeiro: Paz e Terra; 1992.

14. Stotz EM, David MHSL, Wong Un, JA. Educação popular e saúde: trajetória, expressões e desafios de um movimento social. Rev de Atenção Primaria à Saúde [periódico na Internet]. 2005 [acessado 2006 mar 1]. 8(1):1-23. Disponível em: http://www.nates.ufff.br

15. Starfield B. Atenção primária: equilíbrio entre necessidades de saúde, serviços e tecnologia. Brasília: Unesco/M inistério da Saúde; 2004.

16. Brasil. Ministério da Saúde. Secretaria de Políticas de Saúde. Departamento de Atenção Básica. 0 trabalho do agente comunitário de saúde. Brasília: M inistério da Saúde; 2000.
17. Fernandes S. Entrevista realizada com o presidente do Conasems, dr. Silvio Fernandes. Revista do Conasems 2005; 1(12):7-14.

18. Campos GWS. Considerações sobre a arte e a ciência da mudança: revolução das coisas e reforma das pessoas - o caso da saúde. In: Cecílio LCO. Inventando a mudança na saúde. São Paulo: Hucitec; 1997. p. 29-87.

19. Ceccim RB, Bilibio LFS. Observação da educação dos profissionais de saúde: evidências à articulação entre gestores, formadores e estudantes. In: Ceccim RB, Bilibio LFS, organizadores. Observatório de re cursos humanos em saúde no Brasil: estudos e análises. Brasília: Ministério da Saúde; 2002. p. 343-372.

20. Santos LAC. A vez da mulher camponesa: movimento social, identidade e saúde no $M$ aranhão (um relato hirschmaniano). Revista Brasileira de Estudos de População 2003; 20(1):43-62.

21. Herzlich C, Adam P. Sociologia da doença e da medicina. Bauru: Edusc; 2001.

22. Stotz EN. Os desafios para o SU S e a educação popular [site da Internet]. 2003 [acessado 2006 fev 20]. Disponível em: http://www.redepopsaude.com.br

23. Brasil. Ministério da Saúde. Fundação Nacional de Saúde. Programa de Agentes Comunitários de Saúde. Brasília: M inistério da Saúde; 1994.

24. Brasil. M inistério da Saúde. Fundação Nacional de Saúde. Abrindo a porta para a Dona Saúde entrar: uma estratégia para a reorganização do modelo assistencial. Brasília: M inistério da Saúde; 1997.

25. Brasil. M inistério da Saúde. Fundação Nacional de Saúde. M odalidade de contratação de agentes comunitários de saúde: um pacto tripartite. Brasília: M inistério da Saúde; 2002. (Série C: Projetos, Programas e Relatórios).

26. Brandão CR. 0 que é o método Paulo Freire. São Paulo: Brasiliense; 2004.

27. Vasconcelos EM. Educação popular: de uma prática alternativa a uma estratégia de gestão participativa das políticas de saúde. Physis - Revista de Saúde Coletiva 2004; 1(14):67-82.

28. Freire, P. Educação como prática da liberdade. 2 a ed. Rio de Janeiro: Paz e Terra; 2003.

29. Brasil. Ministério da Saúde. Referencial curricular para o Curso Técnico de Agentes Comunitários de Saúde. Brasília: M inistério da Saúde; 2004. (Série A: Normas e M anuais Técnicos).

Artigo apresentado em 13/06/2007

Aprovado em 02/10/2007

Versão final apresentada em 04/12/2007 